\title{
Mobilization in the evening reduces delirium in critically ill patients: the MENTAL randomized, controlled trial
}

Peter Nydahl ( $\sim$ Peter.Nydahl@uksh.de)

Universitatsklinikum Schleswig-Holstein https://orcid.org/0000-0002-5178-0364

David McWilliams

University Hospitals Birmingham NHS Foundation Trust

Norbert Weiler

Universitatsklinikum Schleswig Holstein, Department of Anesthesiology and Intensive Care Medicine

Campus Lubeck Klinik fur Anasthesiologie und Intensivmedizin

Christoph Borzikowsky

Institue of Medical Informatics and Statistics, Kiel University

Fiona Howroyd

University Hospitals Birmingham NHS Foundation Trust

\section{Angelika Brobeil}

University of Heidelberg

\section{Matthias Kott}

University Hospital of Schleswig-Holstein, Department of Anaesthesiology and Intensive Care Medicine

Rebecca von Haken

University Hospital of Mannheim, Department of Anaesthesiology

\section{Research}

Keywords: delirium, early mobilization, Intensive Care Unit, rehabilitation

Posted Date: December 30th, 2019

DOI: https://doi.org/10.21203/rs.2.19733/v1

License: (c) (i) This work is licensed under a Creative Commons Attribution 4.0 International License.

Read Full License 


\section{Abstract}

Background : Delirium is a common complication in patients on Intensive Care Units (ICU). Caring interventions such as early mobilization are effective in prevention and treatment of delirium, but are recommended during daytime. It may be effective in the night, too.

Method : The aim of this study was to prove the effect of mobilization in the evening to prevent or treat ICU patients from delirium. The design was a multicentric, randomized, controlled trial in 5 mixed ICUs over a period of 2 weeks with max. 28 days follow-up. Patients in the intervention group were mobilized onto the edge of the bed or more between 9:00 and 11:00 p.m. by an additional mobilization team, following safety criteria. Patients in the control group received usual care. Primary outcome parameter was the duration of a delirium. Secondary parameters were presence of delirium, mortality, duration of mechanical ventilation (MV) and stay, feasibility, and mobilization-related complications.

Results : In summary, $n=69$ patients could be analysed (intervention $n=36$, control $n=33$ ). Due to limited resources, the trial was stopped and reached $62 \%$ of targeted sample size. Mobilization in the evening did not significantly reduce duration of existing delirium, delirium presence, length of MV or days in ICU and hospital for 28 days follow-up. In an unplanned post-hoc analysis, mobilization in the evening prevented patients from delirium in the first four days (6 (16.7\%) vs. $13(39.4 \%), p=0.032)$, with a number needed to treat of 5 . The intervention was feasible in $71.7 \%$ of eligible patients, with $13.6 \%$ unwanted safety events.

Conclusions : In a mixed ICU population, mobilization in the evening did not show a reduction in duration of delirium, MV or length of stay, but a reduction in the incidence of early onset delirium. Mobilization between 9:00 and 11:00 pm. by an interprofessional mobilization team may prevent patients from delirium. The intervention was feasible, safe, and accepted by most patients.

\section{Background}

One of the most common complications patients experience in Intensive Care Units (ICU) is delirium [1]. Delirium is is characterized by impaired attention and concentration, rapid onset and fluctuating course as well as flawed cognition [2]. Delirium is a direct result of one or more physical disorders, procedures or medications [2, 3]. The causes of a delirium are manifold and result from predisposing and triggering factors [4-7]. The consequences of delirium are an increased risk of prolonged duration of mechanically ventilation (MV) and length of stay, increased mortality, permanent cognitive damage, and institutionalization [8]. The incidence of delirium in ICU patients ranges between $20 \%$ and $89 \%$, in patients on $\mathrm{MV}$ up to $80 \%[9,10]$.

For the prevention and treatment of a delirium, especially caring (non-pharmacological) interventions such as early mobilization are recommended $[8,9,11-13]$. Early mobilization is defined as interventions that support the patient through passive or active movement exercises, with the goal of maintaining or supporting patient mobility [14]. Previous studies of early mobilization during the day have been associated with a reduction in both the incidence and duration of a delirium [15-17]. 
In order to maintain and achieve a normal day-and-night rhythm, mobilization is recommended during the day only, allowing bed rest at night. In more than half of patients with delirium, there is a reversal of the day-and-night rhythm with more sleep hours during the day than at night or nocturnal exacerbation of symptoms $[18,19]$. On the other hand, mobilization may direct agitation, as often seen in patients with hyperactive or mixed type delirium, into controlled pathways. Mobilization may promote their reorientation, potentially normalizing the homeostasis of neurotransmitters through verticalization $[4,20]$. In addition, the physical exertion of mobilization may cause natural sleep to be achieved when patients are later back in bed [8]. A mobilization of patients at night is not uncommon per se, about a fifth to a quarter of out-of-bed mobilizations take place in the evening or at night, albeit unsystematically and for different reasons [21, 22]. A systematic mobilization in the evening could therefore prevent the emergence of a delirium, or positively influence the duration of an existing delirium.

\section{Methods}

The aim of this study was to test following hypothesis: ICU patients who perform gradual mobilization out-of-bed between 9:00 and 11:00 p.m., compared to patients who are treated by usual care, have a reduced duration of delirium. Further hypotheses are to prove the impact of the intervention on a lower incidence of delirium, duration of MV, length of stay in ICU and hospital. Furthermore, the trial was designed to test feasibility, estimation of effect size as well as recruitment rate to conduct future trials. This was an international, multicentre, randomized, controlled trial.

The study was approved by local ethics committees and registered in the German Register for Clinical Trials (DRKS00016859) at Feb. 26th 2019 (www.drks.de). The results of the study are reported in congruence with CONSORT criteria for randomized, controlled trials [23].

\section{Setting}

The study was conducted in five mixed ICUs within three university hospitals in two countries. All ICUs were general ICUs with mixed populations, covering 52 beds in total.

Population

All patients were screened twice daily at 7:00 am and 3:00 p.m. for eligibility. The patients or their legal representatives gave their written informed consent.

In- and exclusion

Patients were included who fulfilled all following conditions: a) $\geq 18$ years old, b) Richmond Agitation Sedation Score (RASS) $\geq-3$ and were responsive, c) could be assessed for delirium, and d) were able to being mobilized out of bed due to local policies, and e) were expected to spend one night on ICU. Excluded were patients who had one or more of the following conditions: a) expectation of death within the next $72 \mathrm{~h}, \mathrm{~b}$ ) no informed consent for the study, c) pre-existing immobility, d) contraindication against mobilization, e) delirium already present before recruitment, f) positive pregnancy test (routinely carried 
out in all patients of childbearing age upon admission to ICU), g) delirium assessment not possible (coma, foreign language, aphasia, etc.), and h) participation in a competitive study with the outcome delirium (see Fig. 1).

\section{Randomisation}

The randomization was done in a 1:1 ratio by an independent researcher based on a query at www.randomizer.org; the group affiliation is coded in $1=$ "intervention group", or $0=$ "control group", the randomization was logged, archived and related to each patient.

Intervention

The intervention of the early mobilization was provided by an additional mobilization team. Mobilization teams have been successfully used in other studies [16, 24]. Mobilization teams were recruited from the study centres and consisted of trained intensive care nurses and/or physiotherapists and could be complemented by medical professionals. Each mobilization team consisted of 2 persons. Each centre had a protocol for mobilization with similar criteria for conducting or withholding mobilization and safety criteria, based on literature [25-27]. The intervention began on day 1, or after patient's consent and randomization. After consultation with the responsible physician and nurse, patients of the intervention group were approached between 9:00-11:00 p.m., informed and mobilized after repeated verbal consent of the patients. The intervention was not delivered in cases where patients were a) already sleeping and unresponsive to verbal questions, b) refused the mobilization, c) in pain, d) not available due to procedures. In shared rooms care was taken to ensure that fellow patients were not disturbed. The mobilization was carried out in compliance with the pre-defined safety criteria. The aim for a minimum mobility level was sitting on the edge of the bed; which if tolerated was progressed to standing, sitting out in a chair or walking. Additional soothing activities such as talking, hair combing, oral care, warm foot baths, back massage, or media use were offered. The duration of the mobilization depended on the tolerance and wishes of the patient [28]. The duration of mobilization was at least 3 minutes and a maximum of 2 hours. Mobilization was stopped at 23:00 and the patient was mobilized back to bed.

The intervention was carried out for three consecutive evenings, a patient may have therefore received the maximum of three interventions. The intervention was terminated if a) inclusion criteria no longer existed, b) after three evenings, c) when the patient has been discharged from the ICU. The intervention has not been continued at secondary wards or units. The study was carried out in June to use the possible effect of dawn most efficiently [29].

\section{Control group}

Patients in the control group received usual care and were mobilized during the day by physiotherapists and nurses. If necessary, they received the same pharmacological treatment as patients in the intervention group, as per local policies. Patients in the control group could be mobilized during the evening, too, on individual judgement of nurses. 
All data were extracted prospectively the patients' charts by the study team or assigned employees. Data included socio-demographical (age, gender, admission diagnosis, co-morbidities, frailty [30]) and care specific data (categorized admission diagnosis, ventilation device, vigilance (Richmond Agitation Sedation Score; RASS), Pain (Numeric Rating Scale, Visual Analog Scala; NRS/VAS), Sequential Organ Failure Assessment, according to [1]. Mobilizations were assessed using the ICU Mobility Scale, a valid, reliable scale ranging from $0=$ "no mobilization" over $3=$ "sitting on the edge of bed" to $10="$ independent walking" [31]. Due to the obvious character of the intervention, blinding was not feasible. The data collection ended at max. 28 days after admission.

Primary and secondary outcome parameters

Duration of a delirium has been assessed with the CAM-ICU as a valid, reliable instrument for delirious detection [32]. The CAM-ICU has been routinely used and documented electronically by clinicians in the centres three times a day since several years. The duration of the delirium is counted in full days; the end of delirium is defined when patients were delirium-negative for $24 \mathrm{~h}$ or discharged. Patients had to be awake and delirium-assessable, or were ranked as unassessable. Secondary outcome parameters such as presence of delirium, duration of MV, length of stay in ICU and hospital, and mortality were collected and followed-up till day 28 after ICU admission. Based on the literature [7], phenotypes of delirium were determined by the physician in charge.

The feasibility of this RCT was tested by a) percentage of recruited patients, b) the rate of patients, actually receiving the intervention, and c) number of safety events (further divided in potential safety events (exceeding a priori defined safety limits, removal of lines or tubes, fall, Borg scale $\geq 7$, stress pain $\geq 5$ ), and safety events leading to consequences (withholding mobilization, re-insertion of lines or tubes, additional treatments) $[33,34]$.

Power-calculation und Financing

Previous studies were able to achieve a $30-50 \%$ reduction in delirium duration and incidence through early mobilization [15-17]. Assuming 5 ICUs with 52 beds, an average length of stay of 4 days and the inclusion of $60 \%$ of all patients, we calculated a total number of 109 patients should be included over a period of 2 weeks (intervention group: 55; control group: 55). With a delirium prevalence of $40 \%(n=44)$ with a duration of 4 days $+/-2$ days, a $50 \%$ reduction in delirium duration by the intervention and a twosided significance level of $p=0.05$, the study would have a power of $90 \%$ to test the hypothesis [35].

The study was funded by the Delirium Research Prize of the German Interdisciplinary Association for Intensive Care and Emergency Medicine (DIVI) and the Philips company, and allowed us to finance several mobility teams in three centres during a study period of 14 days.

Analysis 
Collected variables are reported in frequency tables, means (M) and standard deviations (SD), or medians (MD) and quartiles (IQR), when appropriate. Mann-Whitney-U test, Fisher's Exact Test or independent ttests were used for the analysis of outcome parameters. Due to the confirmatory character of this study, a one-sided $p<0.05$ was used to prove statistical significance. Based on the assumption, that the deliriumprotective impact of early mobilization would last during the intervention period and one following day, an unplanned post-hoc analysis was added to analyse the presence of delirium, Absolute Risk Reduction (ARR) and Number Needed to Treat (NNT) during the first four days after inclusion.

The analysis was carried out using SPSS and validated by a statistician.

\section{Results}

During a 14-days period in June 2019, 226 patients were screened and $76(33.6 \%)$ of patients could be randomized. The intervention was rejected on all three evenings by three (3.9\%) patients, and further four (5.2\%) patients were lost to follow-up, leaving $36(47.4 \%)$ patients for analysis in the intervention- and 33 (43.4\%) patients in the control group (Fig. 1). Due to limited resources, the trial was ended achieving $62.7 \%$ of targeted sample size.

Patient's characteristics were quite similar in the intervention and control group (Table 1). 
Table 1

Patients' characteristics

\begin{tabular}{|c|c|c|c|c|}
\hline Item & All $(n=69)$ & $\begin{array}{l}\text { Intervention group } \\
(n=36)\end{array}$ & $\begin{array}{l}\text { Control group } \\
(n=33)\end{array}$ & $\mathbf{p}$ \\
\hline Male (n, \%) & $45(65.2)$ & $26(72.2)$ & $19(57.6)$ & $\begin{array}{l}0.153 \\
a\end{array}$ \\
\hline Age (mean, SD) & $62.9(14.9)$ & $65.5(11.2)$ & $60.8(17.6)$ & $\begin{array}{l}0.144 \\
b\end{array}$ \\
\hline Weight (mean, SD) & $82.5(18.3)$ & $85.8(18.6)$ & $78.9(17.5)$ & $\begin{array}{l}0.123 \\
b\end{array}$ \\
\hline Dementia (n, \%) & $0(0)$ & $0(0)$ & $0(0)$ & \\
\hline Depression (n, \%) & $1(1.4)$ & $0(0)$ & $1(3.0))$ & $\begin{array}{l}0.478 \\
a\end{array}$ \\
\hline Frailty Scale (Median, IQR) & $4(3-4)$ & $4(3-4)$ & $3.5(3-4)$ & $\begin{array}{l}0.541 \\
c\end{array}$ \\
\hline $\begin{array}{l}\text { Charlson Comorbidity Index } \\
\text { (Median, IQR) }\end{array}$ & $4(2-6)$ & $4(3-6)$ & $3.5(2-6)$ & $\begin{array}{l}0.671 \\
c\end{array}$ \\
\hline SOFA (Median, IQR) & $4(3-6)$ & $4(3-6)$ & $4(3-5)$ & $\begin{array}{l}0.291 \\
c\end{array}$ \\
\hline Highest CRP (Median, IQR) & $\begin{array}{l}69.3 \\
(28.25-161)\end{array}$ & $70.3(42.8-159)$ & $58(17.5-159)$ & $\begin{array}{l}0.327 \\
c\end{array}$ \\
\hline $\begin{array}{l}\text { Highest Procalcitonin (Median, } \\
\text { IQR) }\end{array}$ & $\begin{array}{l}0.56(0.08- \\
2.48)\end{array}$ & $0.53(0.12-5.6)$ & $\begin{array}{l}0.18(0.05- \\
1.34)\end{array}$ & $\begin{array}{l}0.483 \\
c\end{array}$ \\
\hline Highest Lactat (Median, IQR) & $\begin{array}{l}1.95(1.22- \\
8.60)\end{array}$ & $3.1(1.2-10.2)$ & $1.9(1.3-7.4)$ & $\begin{array}{l}0.360 \\
c\end{array}$ \\
\hline Highest Urea (Median, IQR) & $18(5.9-41)$ & $25.5(8.9-46.3)$ & $16.7(5.8-30)$ & $\begin{array}{l}0.329 \\
c\end{array}$ \\
\hline Lowest GFR (Mean, SD) & $\begin{array}{l}73.71 \\
(28.35)\end{array}$ & $76.1(25.9)$ & 73 (31.9) & $\begin{array}{l}0.663 \\
b\end{array}$ \\
\hline
\end{tabular}

Abbreviations: ICU Intensive Care Unit, IQR Interquartile Range, SD Standard Deviation, SOFA Sequential Organ Failure Assessment.

${ }^{a}$ Fishers Exact Test, ${ }^{b}$ independent $\mathrm{t}-\mathrm{Test},{ }^{\mathrm{c}}$ Mann Whithney U Test 


\begin{tabular}{|c|c|c|c|c|}
\hline Item & All $(n=69)$ & $\begin{array}{l}\text { Intervention group } \\
(n=36)\end{array}$ & $\begin{array}{l}\text { Control group } \\
(n=33)\end{array}$ & $\mathbf{p}$ \\
\hline Antibiotics (n, \%) & 64 (92.8) & 34 (94.4) & 30 (90.9) & $\begin{array}{l}0.458 \\
a\end{array}$ \\
\hline Mechanical ventilation $(n, \%)$ & $37(53.6)$ & $23(63.9)$ & $14(42.4)$ & $\begin{array}{l}0.061 \\
\mathrm{a}\end{array}$ \\
\hline $\begin{array}{l}\text { Continuous Renal Replacement } \\
\text { Therapy }(n, \%)\end{array}$ & $3(4.3)$ & $2(5.6)$ & $1(3.0)$ & $\begin{array}{l}0.533 \\
a\end{array}$ \\
\hline Norepinephrine, Milirone ( $\mathrm{n}, \%)$ & $46(66.7)$ & $26(72.2)$ & $20(60.6)$ & $\begin{array}{l}0.222 \\
\mathrm{a}\end{array}$ \\
\hline $\begin{array}{l}\text { Extra Corporal Membrane } \\
\text { Oxygenation }(n, \%)\end{array}$ & $0(0)$ & $0(0)$ & $0(0)$ & - \\
\hline \multicolumn{5}{|c|}{$\begin{array}{l}\text { Abbreviations: ICU Intensive Care Unit, IQR Interquartile Range, SD Standard Deviation, SOFA } \\
\text { Sequential Organ Failure Assessment. }\end{array}$} \\
\hline \multicolumn{5}{|c|}{${ }^{a}$ Fishers Exact Test, ${ }^{b}$ independent t-Test, ${ }^{c}$ Mann Whithney U Test } \\
\hline
\end{tabular}

During the day-time, patients were mobilized in similar patterns in both groups such as (median, IQR) 1 $(0-2)$ times a day, in the level of sitting on the edge of bed, for in mean one hour (Table 2). 
Table 2

Intervention data

\begin{tabular}{|c|c|c|c|c|}
\hline Item & $\begin{array}{l}\text { All }(n \\
=69)\end{array}$ & $\begin{array}{l}\text { Intervention } \\
\text { group }(n=36)\end{array}$ & $\begin{array}{l}\text { Control group } \\
(n=33)\end{array}$ & $\mathbf{p}$ \\
\hline Mobilizations during day time $(\mathrm{n}, \%)$ & $\begin{array}{l}177 \\
(100)\end{array}$ & $93(52.5)$ & $84(47.5)$ & $\begin{array}{l}0.102 \\
a\end{array}$ \\
\hline Frequency per day (median, IQR) & $\begin{array}{l}1(0- \\
2)\end{array}$ & $1(0-2)$ & $1(0-1)$ & $\begin{array}{l}0.334 \\
b\end{array}$ \\
\hline $\begin{array}{l}\text { Highest level of mobilization on ICU } \\
\text { Mobility Scale (mean, SD) }\end{array}$ & $\begin{array}{l}3.3 \\
(2.7)\end{array}$ & $3.5(2.9)$ & $3.1(2.4)$ & $\begin{array}{l}0.274 \\
c\end{array}$ \\
\hline Duration in minutes (mean, SD) & $\begin{array}{l}64.2 \\
(87.6)\end{array}$ & $69.0(84)$ & $58.5(91.9)$ & $\begin{array}{l}0.465 \\
c\end{array}$ \\
\hline $\begin{array}{l}\text { Number of possible mobilizations in the } \\
\text { evening }(n)\end{array}$ & $\begin{array}{l}175 \\
(100)\end{array}$ & $92(52.6)$ & $83(47.4)$ & - \\
\hline Mobilizations took place $(\mathrm{n}, \%)$ & $\begin{array}{l}68 \\
(38.8)\end{array}$ & $66(71.7)$ & $2(2.4)$ & $\begin{array}{l}< \\
0.001 \\
\mathrm{a}\end{array}$ \\
\hline Mobilization declined (n, \%) & $\begin{array}{l}26 \\
(14.9)\end{array}$ & $26(28.3)$ & - & - \\
\hline due to missing staff $(n, \%)$ & $0(0)$ & $0(0)$ & $0(0)$ & - \\
\hline due to patients' refusal $(\mathrm{n}, \%)$ & $14(8)$ & $14(15.2)$ & - & - \\
\hline due to other reasons $(\mathrm{n}, \%)$ & $\begin{array}{l}12 \\
(6.6)\end{array}$ & $12(13)$ & - & - \\
\hline \multicolumn{5}{|c|}{ Abbreviations: IQR Interquartile Range, SD Standard Deviation. } \\
\hline${ }^{a}$ Fishers Exact Test, ${ }^{b}$ Mann-Whitney-U- & nde & at t-Test & & \\
\hline
\end{tabular}

In the intervention group, mobilization was provided in 66 of 92 possible cases (71.7\%). Patients' refusal ( $n=14,15.2 \%$ ) was the most common reason for not carrying out the intervention (Table 2$)$. The complete intervention, including three mobilizations, was received by $47.2 \%(n=17)$ of patients in the intervention group, the others $(n=19,52.8 \%)$ received two or one mobilization, with no dose-response relationship between three vs. less mobilizations and the following outcome parameters.

The primary outcome parameter, duration of delirium, showed no significant differences between both groups (Median (IQR): intervention group: $1.5(1-2.7)$ vs. control group: $2(1-2)$ days, $p=0.860)$. Secondary outcome parameters such as 28-days free of MV, ICU and hospital, and mortality were not significantly different (Table 3). The preventively outcome parameter presence of delirium was lower in the intervention group compared to the control group ( $n=8(22.2 \%)$ vs. $n=13(39.4 \%, p=0.099)$, showing 
a non-significant trend (Table 3). Phenotypes of delirium did not differ significantly between both groups (Table 4).

\section{Table 3}

Outcome parameters

\begin{tabular}{|c|c|c|c|c|}
\hline Item & $\begin{array}{l}\text { All }(n= \\
69)\end{array}$ & $\begin{array}{l}\text { Intervention group } \\
(n=36)\end{array}$ & $\begin{array}{l}\text { Control group } \\
(n=33)\end{array}$ & p \\
\hline 28-days free of delirium (median, IQR) & $\begin{array}{l}28(27- \\
28)\end{array}$ & $28(28-28)$ & $28(26-28)$ & $\begin{array}{l}0.120 \\
b\end{array}$ \\
\hline Presence of delirium $(n, \%)$ & $\begin{array}{l}21 \\
(30.4)\end{array}$ & $8(22.2)$ & $13(39.4)$ & $\begin{array}{l}0.099 \\
\mathrm{a}\end{array}$ \\
\hline $\begin{array}{l}\text { 28-days free of of mechanically } \\
\text { ventilation (median, IQR) }\end{array}$ & $\begin{array}{l}27(26- \\
28)\end{array}$ & $27(25-28)$ & $28(26.5-28)$ & $\begin{array}{l}0.045 \\
b\end{array}$ \\
\hline 28-days free of ICU (median, IQR) & $\begin{array}{l}24 \\
(20.5- \\
25)\end{array}$ & $23(20.2-24)$ & $24(20.5-25)$ & $\begin{array}{l}0.304 \\
b\end{array}$ \\
\hline 28-days free of hospital (median, IQR) & $9(0-17)$ & $3(0-15.7)$ & $11(0-18.5)$ & $\begin{array}{l}0.258 \\
b\end{array}$ \\
\hline Mortality in ICU $(n, \%)$ & $2(2.9)$ & $1(2.9)$ & $1(3.0)$ & $\begin{array}{l}0.739 \\
a\end{array}$ \\
\hline Mortality in hospital $(\mathrm{n}, \%)$ & $1(1.5)$ & $0(0)$ & $1(3.0)$ & $\begin{array}{l}0.485 \\
\mathrm{a}\end{array}$ \\
\hline
\end{tabular}


Table 4

phenotypes of delirium in delirious patients

\begin{tabular}{|lllll|}
\hline Item & $\begin{array}{l}\text { All }(\mathbf{n}= \\
\mathbf{2 1})\end{array}$ & $\begin{array}{l}\text { Intervention } \\
\text { group }(\mathbf{n = 8})\end{array}$ & $\begin{array}{l}\text { Control group } \\
(\mathbf{n = 1 3})\end{array}$ & $\mathbf{p}^{\mathbf{a}}$ \\
\hline $\begin{array}{l}\text { Reasons for delirium in 24 episodes } \\
\text { (multiple choice) (n, \%) }\end{array}$ & $\begin{array}{l}40 \\
(190.5)\end{array}$ & $14(175)$ & $26(200)$ & 1.000 \\
\hline Infections (n, \%) & $\begin{array}{l}21 \\
(100)\end{array}$ & $8(100)$ & $13(100)$ & - \\
\hline Shock (n, \%) & $2(9.5)$ & $0(0)$ & $2(15.4)$ & 0.371 \\
\hline Hypoxia (n, \%) & $2(9.5)$ & $2(25)$ & $0(0)$ & 0.133 \\
\hline Sedation (n, \%) & 9 & $2(25)$ & $7(53.8)$ & 0.201 \\
\hline Metabolic disturbances (n, \%) & $(42.9)$ & & $3(23.1)$ & 0.656 \\
\hline Alcohol/drug withdrawal (n, \%) & 5 & $2(25)$ & $0(0)$ & - \\
\hline Other reasons (n, \%) & $(23.8)$ & & $1(7.7)$ & 0.619 \\
\hline a Fisher Exact Test & $0(0)$ & $0(0)$ & & \\
\hline
\end{tabular}

In a post-hoc analysis of the first four days after inclusion, delirium incidence was significantly lower in the intervention group compared to the control group $(n=6(16.7 \%)$ vs. $n=13(39.4 \%), p=0.032)$. The ARR is $22.73 \%(2.08-43.37 \%)$, NNT is 5 to prevent one patient from delirium.

All patients were awake (RASS $=0)$, and the majority were spontaneously breathing $(n=53,80.3 \%$;

Table 5). The median level of mobilization was 4="standing in front of bed" (IQR $3=$ "sitting on the edge of bed" till $6=$ "marching on spot"). During the mobilization, 136 activities in total were delivered, mostly talks ( $n=61,92.4 \%)$. In most cases $(n=57,86.4 \%)$, mobilization was well tolerated, with deviation of systolic blood pressure $>20 \%$ as most often unwanted safety event $(n=4,6 \%)$. Consequences of safety events appeared in $10.6 \%$ of mobilizations, mostly stopping mobilization $(n=4,6 \%)$. No patient required re-/insertions of lines or tubes, or cardiopulmonary resuscitation. Therefore, the intervention can be evaluated as feasible and safe. 
Table 5

Mobilization data of the intervention group

\begin{tabular}{|c|c|}
\hline Item & Mobilizations $(n=66)$ \\
\hline Richmond Agitation Sedation Scale (Median, IQR) & $0(0-0)$ \\
\hline Pain $(0-10)$ (Median, IQR) & $0(0-2)$ \\
\hline \multicolumn{2}{|l|}{ Mode of breathing } \\
\hline Spontaneous breathing $(\mathrm{n}, \%)$ & $53(80.3)$ \\
\hline Endotracheal Tube $(n, \%)$ & $4(6.1)$ \\
\hline Tracheostomia Tube $(\mathrm{n}, \%)$ & $6(9.1)$ \\
\hline Non-Invasive Ventilation/Nasal Highflow Therapy (n, \%) & $3(4.5)$ \\
\hline Mobilization Level (Median, IQR) & $4(3-6)$ \\
\hline Duration (Median, IQR) & $20(15-30)$ \\
\hline Activities during 66 mobilizations ( $\mathrm{n}, \%)$ & $136(206.1)$ \\
\hline Talk (n, \%) & $61(92.4)$ \\
\hline Massage on the back $(n, \%)$ & $39(59.1)$ \\
\hline Combing hairs $(n, \%)$ & $17(25.7)$ \\
\hline Mouth Care $(n, \%)$ & $14(21.2)$ \\
\hline Media (TV, Radio, Smartphone) (n, \%) & $5(7.6)$ \\
\hline Footbath (n, \%) & $0(0)$ \\
\hline \multicolumn{2}{|l|}{ Unwanted Safety Events during 66 mobilizations } \\
\hline Well tolerated $(n, \%)$ & $57(86.4)$ \\
\hline Any unwanted safety event (n, \%) & $9(13.6)$ \\
\hline Heart frequency $>220$ - age $(n, \%)$ & $0(0)$ \\
\hline Deviation systolic blood pressure $>20 \%(n, \%)$ & $4(6)$ \\
\hline Deviation Oxygen Saturation $>5 \%(n, \%)$ & $1(1)$ \\
\hline Fall $(n, \%)$ & $0(0)$ \\
\hline Borg Scale > $6(n, \%)$ & $2(2)$ \\
\hline Pain under strain $>4(n, \%)$ & $1(1)$ \\
\hline Removal of lines or tubes $(n, \%)$ & $1(1)$ \\
\hline
\end{tabular}




\begin{tabular}{|ll|}
\hline Item & Mobilizations $(\mathbf{n}=66)$ \\
\hline Consequences of safety events & $7(10.6)$ \\
\hline Stopping mobilization $(\mathrm{n}, \%)$ & $4(6)$ \\
\hline Additional drugs $(\mathrm{n}, \%)$ & $2(3)$ \\
\hline Additional fluids $(\mathrm{n}, \%)$ & $1(1.5)$ \\
\hline Re-/Insertion of lines or tubes $(\mathrm{n}, \%)$ & $0(0)$ \\
\hline Plaster change $(\mathrm{n}, \%)$ & $0(0)$ \\
\hline Cardiopulmonary resuscitation $(\mathrm{n}, \%)$ & $0(0)$ \\
\hline
\end{tabular}

\section{Discussion}

In this multicentre, randomized, controlled trial including $\mathrm{n}=69$ patients on mixed ICUs, a mobilization in the evening between 9:00 and 11:00 p.m. by an additional mobility team did not reduce duration of delirium, length of MV or days in ICU and hospital, but showed a trend in preventing delirium. The trial ended before reaching the targeted sample size. In an unplanned sub-analysis during the first four days after inclusion, the NNT to prevent delirium is 5 . The intervention was accepted by three quarters of the recruited patients, with a low rate of unwanted safety events.

Although our intervention failed to demonstrate a reduction in the duration of delirium, there was a possible reduction in the incidence for those patients mobilised in the evening in comparison to controls. These results are similar to a recent meta-analysis [36]. One theory to support this finding could be that the evening mobilisation facilitated better sleep in the intervention group, thus, preventing the onset of sleep deprivation and delirium. However, as no direct measurements of sleep duration or quality were taken, this cannot be evaluated as part of this trial. Mobilization in the evening may also reduce delirium contributing factors such as immobility, sleep disorders or hormonal misbalance and others [3]. Another hypothesis is that early mobilisation improves brain function by keeping the homeostasis of neurotransmitters, and facilitation of synaptic transmission and promotion of neurogenesis and angiogenesis [37]. The question raises how long an effect of mobilization may last to prevent patients from delirium? In our unplanned sub-analysis, we assumed a preventive effect during the intervention phase plus one day. Can one assume that the delirium preventive effect of mobilization would last for one or two weeks? More research is needed to evaluate the best combination of frequency, duration, intensity and time of mobilization for suitable patients to prevent delirium.

Once delirium was present, mobilisation in the evening may have been insufficient to re-orientate patients and aid in delirium resolution. Although additional reorientation strategies were included in our protocol, this predominantly consisted of talking with the patient (92\%) or back massage (59\%). Anecdotally, we observed a reduction in delirium severity by mobilizing agitated patients, but delirium severity was not 
systematically assessed. Specific delirium phenotypes could not be identified, which would have the best benefit from mobilization, to conclude to a particular caring treatment. It might be reasonable that mobilization can worsen a delirium, which is caused by shock and reduced cerebral perfusion, but may improve a delirium caused by sedation, hypoxia or metabolic disturbances. Future trials may benefit from providing a more structured approach to reorientation in combination with evening mobilisation and evaluate the effect of mobilization on severity of delirium.

Due to limited resources, the targeted sample size has not been achieved. The research grant has been used for payment of the mobility teams, and after two weeks, we ran out of money. Actually, we overestimated the need for mobility teams, and found that one team of two clinicians instead of two teams were sufficient to mobilize patients on three ICUs. Furthermore, the preventive effect of the intervention led to a lesser number of delirious patients in the intervention group, lowering the total number of delirious patients. Based on the current results, we calculated for the primary, resp. secondary outcome parameters that a total of $n=398$, resp. $n=198$ patients in intervention and control group would have been needed to reach a statistical power of $80 \%$, when assuming a small effect size of $d=0.25$ and a one-sided $5 \%$ significance level. Overall, the study was underpowered, which hampers the interpretation of our results. We cannot exclude type 1 errors and recommend larger trials to confirm or revise the results.

Our study has some limitations that should be addressed as well. First, as mentioned above, the study was underpowered. Second, the three participating hospitals have well established bundles for delirium prevention and mobilization, as reflected in an overall low incidence for delirium. Third, for financial reasons patients were only additionally mobilized on three consecutive evenings, which might be too short to show a significant effect of mobilization. Strengths of the study are the multi-centre design, a pre-planned analysis, a comparable mobilization-protocol, and the development of future research hypotheses.

\section{Conclusions}

In mixed ICU patients, mobilization did not show a reduction in duration of delirium, MV or length of stay, but a reduction in the incidence of early onset delirium. Mobilization between 9:00 and 11:00 p.m. by an interprofessional mobilization team may prevent mixed ICU patients from delirium. Mobilization in the evening is a feasible and safe intervention in the ICU. Three of four patients accept the intervention. In one out of ten patients, mobilization was premature ended, mostly due to a low blood pressure or exertion. It will require further studies to examine the possible impact of late mobilization throughout the ICU stay on incidence as well as on duration and severity of delirium.

\section{Decarations}

\section{Ethics approval and consent to participate}


The study was approved by local ethics committees and registered in the German Register for Clinical Trials (DRKS00016859).

\section{Consent for publication}

Not applicable

\section{Availability of data and material}

The datasets during and/or analysed during the current study available from the corresponding author on reasonable request.

\section{Competing interests}

- PN received the Delirium Research Prize of the German Interdisciplinary Association for Intensive Care and Emergency Medicine (DIVI) and the Philips company

- $\mathrm{RvH}$ received the Delirium Research Prize of the German Interdisciplinary Association for Intensive Care and Emergency Medicine (DIVI) and the Philips company. She received speaker-fees from Orionpharma, as well as travel funding

- DM has received speaker fees from Arjo, as well as travel funding

- $\mathrm{AB}, \mathrm{CB}, \mathrm{FH}, \mathrm{MK}$, and NW report no conflicts

\section{Funding}

This is work is funded by the Delirium Research Prize of the German Interdisciplinary Association for Intensive Care and Emergency Medicine (DIVI) and the Philips company. Both entities did not have any influence in designing, conducting, analysing, interpreting, or writing the study.

\section{Author's contributions}

$\mathrm{PN}, \mathrm{DM}, \mathrm{NW}, \mathrm{NK}$, and RvH developed the concept and design of this study, PN, MK, DM, FH, AB and RVH assessed the data. PN, CB, NW, MK, RvH analysed and interpreted the data. PN drafted the manuscript. All authors read and approved the final manuscript and are personally accountable for the accuracy and integrity of this work.

\section{Acknowledgement}

We are grateful for all clinicians and patients who supported this study and helped with mobilization in the evening.

\section{References}

1. Devlin JW, Skrobik Y, Gelinas C, Needham DM, Slooter AJC, Pandharipande PP, Watson PL, Weinhouse GL, Nunnally ME, Rochwerg B, Balas MC, van den Boogaard M, Bosma KJ, Brummel NE, 
Chanques G, Denehy L, Drouot X, Fraser GL, Harris JE, Joffe AM, Kho ME, Kress JP, Lanphere JA, McKinley S, Neufeld KJ, Pisani MA, Payen JF, Pun BT, Puntillo KA, Riker RR, Robinson BRH, Shehabi Y, Szumita PM, Winkelman C, Centofanti JE, Price C, Nikayin S, Misak CJ, Flood PD, Kiedrowski K, Alhazzani W, (2018) Clinical Practice Guidelines for the Prevention and Management of Pain, Agitation/Sedation, Delirium, Immobility, and Sleep Disruption in Adult Patients in the ICU. Crit Care Med 46: e825-e873

2. American-Psychiatric-Association (2013) Diagnostic and Statistical Manual of Mental Disorders. In: Editor (ed)^(eds) Book Diagnostic and Statistical Manual of Mental Disorders. American Psychiatric Association, Arlington, City, pp.

3. Meyfroidt G, Smith M, (2019) Focus on delirium, sedation and neuro critical care 2019: towards a more brain-friendly environment? Intensive Care Med 45: 1292-1294

4. Maldonado JR, (2008) Pathoetiological model of delirium: a comprehensive understanding of the neurobiology of delirium and an evidence-based approach to prevention and treatment. Crit Care Clin 24: 789-856, ix

5. Müllges W, (2014) Ätiologie und Therapie des Delirs. Aktuelle Neurologie 4: 586-596

6. Nydahl P, Margraf NG, Ewers A, (2017) [Delirium in stroke patients : Critical analysis of statistical procedures for the identification of risk factors]. Med Klin Intensivmed Notfmed

7. Girard TD, Thompson JL, Pandharipande PP, Brummel NE, Jackson JC, Patel MB, Hughes CG, Chandrasekhar R, Pun BT, Boehm LM, Elstad MR, Goodman RB, Bernard GR, Dittus RS, Ely EW, (2018) Clinical phenotypes of delirium during critical illness and severity of subsequent long-term cognitive impairment: a prospective cohort study. Lancet Respir Med 6: 213-222

8. Oh ES, Fong TG, Hshieh TT, Inouye SK, (2017) Delirium in Older Persons: Advances in Diagnosis and Treatment. JAMA 318: 1161-1174

9. DAS-Taskforce, Baron R, Binder A, Biniek R, Braune S, Buerkle H, Dall P, Demirakca S, Eckardt R, Eggers V, Eichler I, Fietze I, Freys S, Fründ A, Garten L, Gohrbandt B, Harth I, Hartl W, Heppner H-J, Horter J, Huth R, Janssens U, Jungk C, Kaeuper KM, Kessler P, Kleinschmidt S, Kochanek M, Kumpf M, Meiser A, Mueller A, Orth M, Putensen C, Roth B, Schaefer M, Schaefers R, Schellongowski P, Schindler M, Schmitt R, Scholz J, Schroeder S, Schwarzmann G, Spies C, Stingele R, Tonner P, Trieschmann U, Tryba M, Wappler F, Waydhas C, Weiss B, Weisshaar G, (2015) Evidence and consensus based guideline for the management of delirium, analgesia, and sedation in intensive care medicine. Revision 2015 (DAS-Guideline 2015) - short version. Ger Med Sci 13: Doc19

10. Collet MO, Caballero J, Sonneville R, Bozza FA, Nydahl P, Schandl A, Woien H, Citerio G, van den Boogaard M, Hastbacka J, Haenggi M, Colpaert K, Rose L, Barbateskovic M, Lange T, Jensen A, Krog MB, Egerod I, Nibro HL, Wetterslev J, Perner A, (2018) Prevalence and risk factors related to haloperidol use for delirium in adult intensive care patients: the multinational AID-ICU inception cohort study. . Intensive Care Med

11. Barr J, Fraser GL, Puntillo K, Ely EW, Gélinas C, Dasta JF, Davidson JE, Devlin JW, Kress JP, Joffe AM, Coursin DB, Herr DL, Tung A, Robinson BRH, Fontaine DK, Ramsay MA, Riker RR, Sessler CN, Pun B, 
Skrobik Y, Jaeschke R, Medicine ACoCC, (2013) Clinical practice guidelines for the management of pain, agitation, and delirium in adult patients in the intensive care unit. Crit Care Med 41:263-306

12. Nydahl P, Dewes M, Dubb R, Hermes C, Kaltwasser A, Krotsetis S, von Haken R, (2017) Survey among critical care nurses and physicians about delirium management. Nurs Crit Care

13. Krotsetis S, Nydahl P, Dubb R, Hermes C, Kaltwasser A, von Haken R, (2017) Status quo of delirium management in German-speaking countries: comparison between intensive care units and wards. Intensive Care Medicine

14. Bein T, Bischoff M, Bruckner U, Gebhardt K, Henzler D, Hermes C, Lewandowski K, Max M, Nothacker M, Staudinger T, Tryba M, Weber-Carstens S, Wrigge H, (2015) S2e guideline: positioning and early mobilisation in prophylaxis or therapy of pulmonary disorders : Revision 2015: S2e guideline of the German Society of Anaesthesiology and Intensive Care Medicine (DGAI). Anaesthesist 64 Suppl 1: 126

15. Needham DM, Korupolu R, Zanni JM, Pradhan P, Colantuoni E, Palmer JB, Brower RG, Fan E, (2010) Early physical medicine and rehabilitation for patients with acute respiratory failure: a quality improvement project. Arch Phys Med Rehabil 91: 536-542

16. Schweickert WD, Pohlman MC, Pohlman AS, Nigos C, Pawlik AJ, Esbrook CL, Spears L, Miller M, Franczyk M, Deprizio D, Schmidt GA, Bowman A, Barr R, McCallister KE, Hall JB, Kress JP, (2009) Early physical and occupational therapy in mechanically ventilated, critically ill patients: a randomised controlled trial. Lancet 373: 1874-1882

17. Schaller SJ, Anstey M, Blobner M, Edrich T, Grabitz SD, Gradwohl-Matis I, Heim M, Houle T, Kurth T, Latronico N, Lee J, Meyer MJ, Peponis T, Talmor D, Velmahos GC, Waak K, Walz JM, Zafonte R, Eikermann M, Initiative IES-gMR, (2016) Early, goal-directed mobilisation in the surgical intensive care unit: a randomised controlled trial. Lancet 388: 1377-1388

18. Flannery AH, Oyler DR, Weinhouse GL, (2016) The Impact of Interventions to Improve Sleep on Delirium in the ICU: A Systematic Review and Research Framework. Crit Care Med

19. Dilling H, Mombour W, Schmidt MH (2011) Internationale Klassifikation psychischer Störungen: ICD10 Kapitel V (F); klinisch-diagnostische Leitlinien. Huber, Bern

20. Nydahl P, Günther U, Krotsetis S, (2014) Delirium and early mobilisation. Annals of Delirium Care 14: 13-17

21. Cortes OL, DiCenso A, McKelvie R, (2015) Mobilization patterns of patients after an acute myocardial infarction: a pilot study. Clin Nurs Res 24: 139-155

22. Nydahl P, Dewes M, Dubb R, Filipovic S, Hermes C, Juttner F, Kaltwasser A, Klarmann S, Klas K, Mende H, Rothaug O, Schuchhardt D, Netzwerk F, (2016) Early Mobilization: competencies, responsibilities and accountabilities (German: Frühmobilisierung: Kompetenzen, Verantwortungen, Zuständigkeiten). Med Klin Intensivmed Notfmed 111: 153-159

23. Moher D, Hopewell S, Schulz KF, Montori V, Gotzsche PC, Devereaux PJ, Elbourne D, Egger M, Altman DG, (2010) CONSORT 2010 explanation and elaboration: updated guidelines for reporting parallel group randomised trials. Bmj 340: c869 
24. Morris PE, Goad A, Thompson C, Taylor K, Harry B, Passmore L, Ross A, Anderson L, Baker S, Sanchez M, Penley L, Howard A, Dixon L, Leach S, Small R, Hite RD, Haponik E, (2008) Early intensive care unit mobility therapy in the treatment of acute respiratory failure. Crit Care Med 36: 2238-2243

25. Hodgson CL, Stiller K, Needham DM, Tipping CJ, Harrold M, Baldwin CE, Bradley S, Berney S, Caruana LR, Elliott D, Green M, Haines K, Higgins AM, Kaukonen KM, Leditschke IA, Nickels MR, Paratz J, Patman S, Skinner EH, Young PJ, Zanni JM, Denehy L, Webb SA, (2014) Expert consensus and recommendations on safety criteria for active mobilization of mechanically ventilated critically ill adults. Crit Care 18: 658

26. Nydahl P, Gunther U, Diers A, Hesse S, Kerschensteiner C, Klarmann S, Borzikowsky C, Kopke S, (2019) PROtocol-based MObilizaTION on intensive care units: stepped-wedge, cluster-randomized pilot study (Pro-Motion). Nurs Crit Care

27. McWilliams D, Jones C, Atkins G, Hodson J, Whitehouse T, Veenith T, Reeves E, Cooper L, Snelson C, (2018) Earlier and enhanced rehabilitation of mechanically ventilated patients in critical care: A feasibility randomised controlled trial. Journal of Critical Care 3: 407-412

28. Borg G, (2004) Anstrengungsempfinden und körperliche Aktivität. Dtsch Ärztebl 101: 1016-1021

29. Weiss B, Spies C, Piazena H, Penzel T, Fietze I, Luetz A, (2016) Exposure to light and darkness and its influence on physiological measures of intensive care unit patients-a systematic literature review. Physiological measurement 37: R73-87

30. Rockwood K, Song X, MacKnight C, Bergman H, Hogan DB, McDowell I, Mitnitski A, (2005) A global clinical measure of fitness and frailty in elderly people. CMAJ 173: 489-495

31. Hodgson C, Needham D, Haines K, Bailey M, Ward A, Harrold M, Young P, Zanni J, Buhr H, Higgins A, Presneill J, Berney S, (2014) Feasibility and inter-rater reliability of the ICU Mobility Scale. Heart Lung 43: $19-24$

32. Gusmao-Flores D, Salluh JIF, Chalhub RÁ, Quarantini LC, (2012) The confusion assessment method for the intensive care unit (CAM-ICU) and intensive care delirium screening checklist (ICDSC) for the diagnosis of delirium: a systematic review and meta-analysis of clinical studies. Crit Care 16: R115

33. Nydahl P, Sricharoenchai T, Chandra S, Kundt FS, Huang M, Fischill M, Needham DM, (2017) Safety of Patient Mobilization and Rehabilitation in the Intensive Care Unit. Systematic Review with MetaAnalysis. Ann Am Thorac Soc 14: 766-777

34. Eldridge SM, Chan CL, Campbell MJ, Bond CM, Hopewell S, Thabane L, Lancaster GA, (2016) CONSORT 2010 statement: extension to randomised pilot and feasibility trials. Bmj 355: i5239

35. Kane SP (2017) Sample Size Calculator. In: Editor (ed)^(eds) Book Sample Size Calculator. City, pp.

36. Haley MN, Casey P, Kane RY, Darzins P, Lawler K, (2019) Delirium management: Let's get physical? A systematic review and meta-analysis. Australasian journal on ageing

37. Hopkins RO, Suchyta MR, Farrer TJ, Needham D, (2012) Improving post-intensive care unit neuropsychiatric outcomes: understanding cognitive effects of physical activity. Am J Respir Crit Care Med 186: 1220-1228 

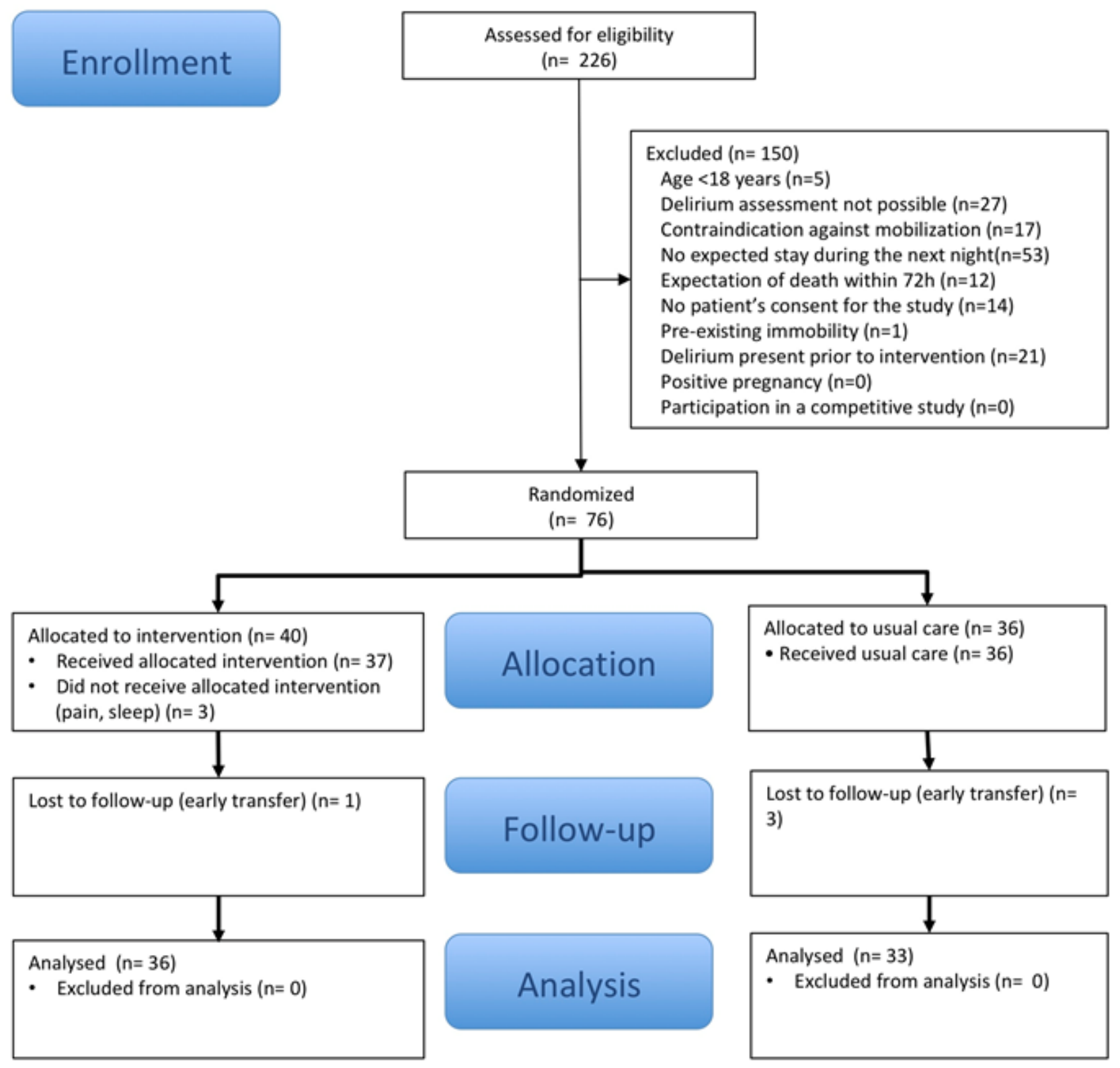

Figure 2

Patients' flow diagram 
This is a list of supplementary files associated with this preprint. Click to download.

- Supplement.docx

- Supplement.docx 